\title{
rhErythropoietin-b as a tissue protective agent in kidney transplantation: a pilot randomized controlled trial
}

Beatrice Coupes ${ }^{1 *}$, Declan G de Freitas ${ }^{1}$, Stephen A Roberts ${ }^{2}$, lan Read ${ }^{1}$, Hany Riad ${ }^{3}$, Paul EC Brenchley ${ }^{1}$ and Michael L Picton ${ }^{1}$

\begin{abstract}
Background: Extended criteria donor (ECD) and donation after circulatory death (DCD) kidneys are at increased risk of delayed graft function (DGF). Experimental evidence suggests that erythropoietin (EPO) attenuates renal damage in acute kidney injury. This study piloted the administration of high dose recombinant human EPO-beta at implantation of ECD and DCD kidneys, and evaluated biomarkers of kidney injury post-transplant.

Methods: Forty patients were randomly assigned to receive either rhEPO-b (100,000 iu) $(n=19$ in the intervention group, as 1 patient was un-transplantable post randomisation), or placebo $(n=20)$ in this, double blind, placebo-controlled trial at Manchester Royal Infirmary from August 2007 to June 2009. Participants received either an ECD $(n=17)$ or DCD $(n=22)$ kidney. Adverse events, renal function, haematopoietic markers, and rejections were recorded out to 90 days post-transplant. Biomarkers of kidney injury (neutrophil gelatinase-associated lipocalin, Kidney Injury Molecule-1 and IL-18) were measured in blood and urine during the first post-operative week.
\end{abstract}

Results: The incidence of DGF (53\% vs 55\%) (RR=1.0; $\mathrm{Cl}=0.5-1.6 ; \mathrm{p}=0.93)$ and slow graft function (SGF) (32\% vs 25\%) $(R R=1.1 ; C l=0.5-1.9 ; p=0.73)$ respectively, serum creatinine, eGFR, haemoglobin and haematocrit, blood pressure, and acute rejection were similar in the 2 study arms. High dose rhEPO-b had little effect on the temporal profiles of the biomarkers.

Conclusions: High dose rhEPO-b appears to be safe and well tolerated in the early post- transplant period in this study, but has little effect on delayed or slow graft function in recipients of kidneys from DCD and ECD donors. Comparing the profiles of biomarkers of kidney injury (NGAL, IL-18 and KIM-1) showed little difference between the rhEPO-b treated and placebo groups. A meta-analysis of five trials yielded an overall estimate of the RR for DGF of 0.89 $(\mathrm{Cl}=0.73 ; 1.07)$, a modest effect favouring EPO but not a significant difference. A definitive trial based on this estimate would require 1000-2500 patients per arm for populations with base DGF rates of 50-30\% and 90\% power. Such a trial is clearly unfeasible.

Trial registration: EudraCT Number 2006-005373-22 ISRCTN ISRCTN85447324 registered 19/08/09.

Keywords: Ischaemia reperfusion, Delayed graft function, Erythropoietin

\footnotetext{
* Correspondence: beatrice.coupes@manchester.ac.uk

'Department of Renal Medicine, Manchester Royal Infirmary, Oxford Rd, Manchester M13 9WL, UK

Full list of author information is available at the end of the article
} 


\section{Background}

In 2011-2012, 34\% of UK deceased donors were over the age of 60 yrs while $40 \%$ were donation after circulatory death (DCD) donors [1]. Both expanded criteria donors (ECD) and DCD kidneys are more likely to develop delayed graft function (DGF) in the early post-transplant period [2,3], with its ensuing clinical and financial implications. Since its introduction, recombinant human erythropoietin has been a major advance in the management of renal anaemia, enhancing patient cognitive function, physical activity and quality of life [4,5]. In addition, there is now a large body of evidence that rhEPO has pleiotropic effects on the body beyond the erythroid compartment. Animal studies examining acute kidney injury, including ischaemia reperfusion injury (IRI) have shown functional improvements [6,7], and antiinflammatory effects [8] after EPO administration, either before $[9,10]$, during $[11,12]$, or very importantly, after the injury has taken place [6,7,12]. In 2002, Ehrenreich et al. [13] reported a human study in acute ischemic stroke, where high-dose rhEPO was well tolerated and associated with an improvement in outcome at 1 month, as assessed by clinical endpoints of stroke and outcome scales.

Based on results from clinical trials including 1725 patients approximately $8 \%$ of patients treated with NeoRecormon $^{\odot}$ are expected to experience adverse reactions. Undesirable effects are observed predominantly in patients with chronic renal failure or underlying malignancies and are most commonly an increase in blood pressure or aggravation of existing hypertension and headache. The therapeutic margin of NeoRecormon ${ }^{\circledR}$ is very wide. Even at very high serum levels no symptoms of poisoning have been observed [14].

Against this background of evidence supporting the theory that administration of rhEPO after injury may be beneficial, we performed a pilot study to assess the safety of administering high dose rhEPO-beta to ECD and DCD kidney recipients intra- and peri-operatively, to obtain preliminary data on efficacy, and to evaluate changes in three extensively reported biomarkers of kidney injury in blood and urine: NGAL [15,16], IL-18 [17], and KIM-1 $[18,19]$, during the first post-operative week.

\section{Results}

\section{Patients}

Eighty-two recipients were screened (Figure 1) providing 63 eligible candidates 34 donors contributed 39 kidneys, with 5 DCD's contributing a single kidney into both the rhEPO-b and placebo treated groups. Thirty-nine patients were transplanted, 19 in the rhEPO-b treated group (one patient in the intervention arm was deemed untransplantable following randomisation), and 20 in the placebo group. No difference was seen in age, sex, ethnicity and BMI of the donor between the groups. Donor cause of death was predominantly an intra-cerebral event in $>75 \%$ of cases. The rhEPO-b group received more DCD kidneys (63\% vs 50\%, $\mathrm{p}=0.41$ ), particularly DCD kidneys meeting extended criteria ( $33 \%$ vs $20 \%, \mathrm{p}=0.65$ ). One patient withdrew from the trial following the initial rhEPO-b dose, due to an event attributed to an arterial intimal flap and unrelated to the study drug, but consented to allow continued collection of samples and follow-up data. The patient was included in the final analysis on an intention to treat basis. Demographics for donors and recipients are shown in Table 1. One patient in the rhEPO-b treated group received ATG induction, due to a weakly positive flow cross-match in accordance with transplant unit policy.

\section{Pre-transplant dialysis}

In the rhEPO-b group 5/19 received 2 hours of haemodialysis and one patient received rapid cycling peritoneal dialysis with varying degrees of ultrafiltration immediately prior to surgery. Of these, four patients subsequently developed DGF. In the placebo group 4/20 received 2 hours of haemodialysis prior to surgery and all developed DGF. Of interest, 17/21 patients on maintenance haemodialysis prior to surgery developed DGF, as opposed to 3/15 patients on maintenance peritoneal dialysis (RR 4.05; CI 1.44-11.38; $\mathrm{p}=0.0005)$.

\section{Adverse events}

There were two deaths due to sepsis in the placebo group. Hypertension occurred in 6 rhEPO-b recipients and 5 patients in the placebo group $(\mathrm{RR}=0.79 ; \mathrm{CI}=0.29-2.17$; $\mathrm{p}=0.73)$. One patient in the rhEPO-b group developed a generalised tonic-clonic seizure due to severe hypertension, attributed to hypervolaemia and the cessation of anti-hypertensive medication peri-operatively (unit policy). In the opinion of the respective attending consultants and the independent trial data monitor, none of the observed adverse events was attributable to rhEPO-b treatment.

\section{Graft function early post-transplant}

Numbers and duration of dialysis episodes were similar in both groups (Table 2). DCD kidney recipients were more likely to develop DGF $(15 / 22)$ than ECD kidney recipients $(5 / 17) \quad(\mathrm{RR}=2.47 ; \quad \mathrm{CI}=1.13-5.39 ; \quad \mathrm{p}=0.01)$. Seven of 12 DCD recipients in the rhEPO-b group and $8 / 10$ in the placebo group developed DGF $(R R=1.37$; $\mathrm{CI}=0.77-2.42 ; \mathrm{p}=0.38)$. Similarly $2 / 7 \mathrm{ECD}$ recipients in the rhEPO-b group and $3 / 10$ in the placebo group developed DGF $(\mathrm{RR}=1.05 ; \mathrm{CI}=0.23-4.73 ; \mathrm{p}=1.0)$. The most common indication for first dialysis was hyperkalaemia.

\section{Graft function out to 90 days post-transplant}

Sequential serum creatinine and 4-variable MDRD eGFR are shown in Figure 2A and B respectively. Kidney 


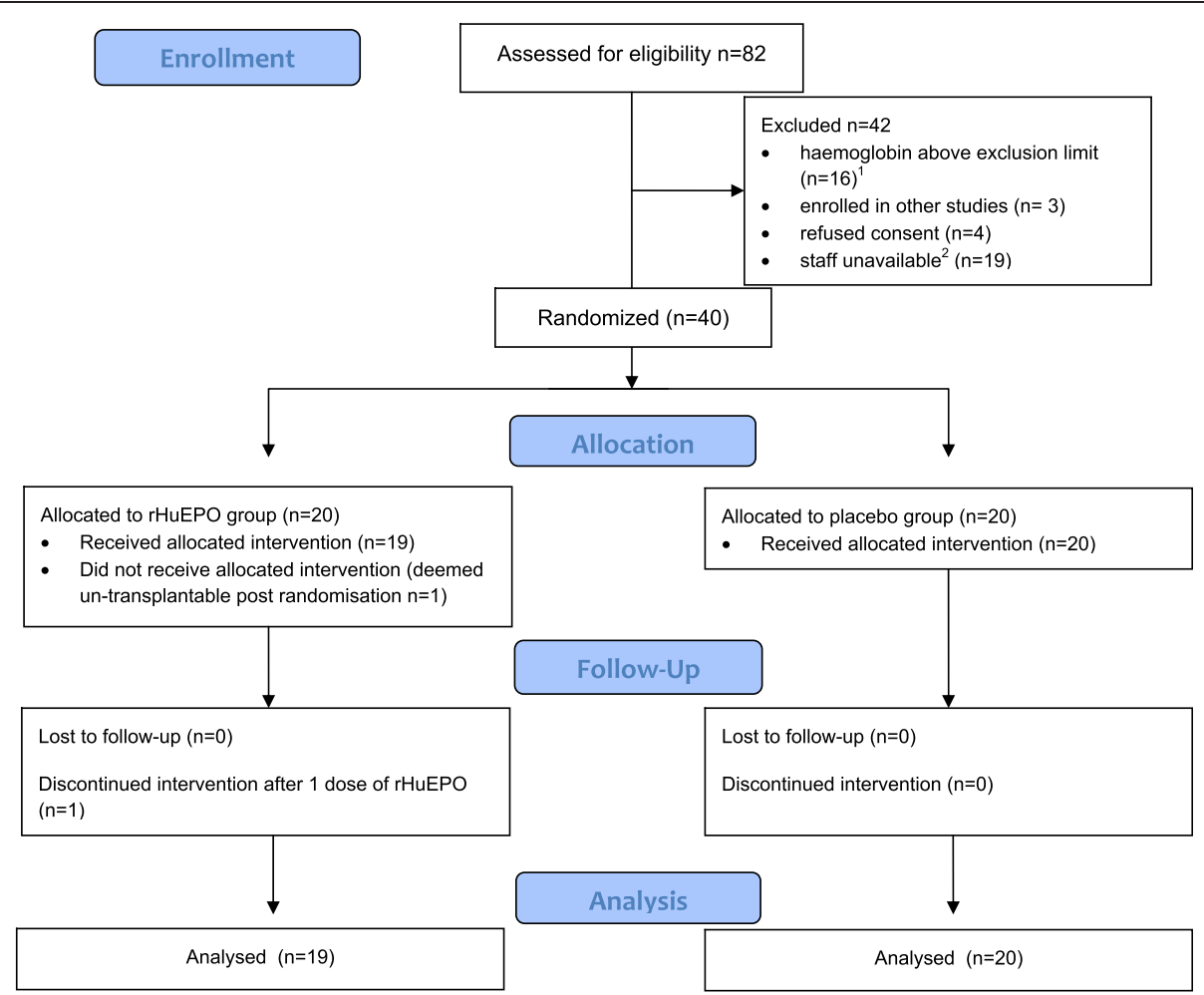

Figure 1 Screening and randomisation. ${ }^{1}$ The exclusion limit for haemoglobin was raised to $15 \mathrm{~g} / \mathrm{dl}$ as a substantial amendment to the protocol with ethical and regulatory authority approval. ${ }^{2}$ The study staff trained in the blinded sequence of delivering the intervention were not always available for out of hours transplants.

function (eGFR) was not analysed prior to day 7, apart from baseline pre-transplant, due to the high rate of DGF and the impact of dialysis, preventing meaningful analysis. Acute rejection rates were similar in the rhEPO$\mathrm{b}$ treated and placebo groups during the first 3 months post-transplant ( 5 vs 3 ; $\mathrm{RR}=0.57 ; \mathrm{CI}=0.16-2.1 ; \mathrm{p}=0.45$ ).

\section{Haematological parameters}

Haemoglobin levels were similar in the rhEPO-b and placebo groups on entry into the study $(11.5 \pm 0.3 \mathrm{~g} / \mathrm{dl} v s$ $11.3 \pm 0.4 \mathrm{~g} / \mathrm{dl}$, respectively; $\mathrm{p}=0.78$ ). The number of blood transfusions required during the in-patient stays did not differ significantly between groups $(p=0.20)$ and the groups had similar levels of maintenance rhEPO-b usage post- transplant (Table 1). There was no effect on platelet levels at any time point (data not shown). Haemoglobin and haematocrit profiles are shown in Figure $2 \mathrm{C}$ and $\mathrm{D}$ respectively, showing no significant differences between the groups.

\section{Biomarkers}

The temporal profiles in blood and urine of the biomarkers of renal injury, neutrophil gelatinase-associated lipocalin (NGAL), Kidney Injury Molecule-1 (KIM-1) and, IL-18 are shown in Figure 3A-E. There were small differences between the rhEPO-b and placebo treated groups, none of which reached statistical significance.

\section{Meta-analysis of 5 trials of rhEPO in transplantation}

A meta-analysis (Figure 4) including data from this trial and from those described by Sureshkumar et al. [20], Hafer et al. [21], Martinez et al. [22] and Aydin et al. [23] yielded an overall estimate of the RR for DGF of $0.89(\mathrm{CI}=0.73 ; 1.07)$, a modest effect favouring rhEPO, but not demonstrating a significant difference between rhEPO and placebo treatments.

\section{Discussion}

This pilot study supported the view that the intra- and peri-operative intra-venous administration of high dose rhEPO-b (a total infusion of 100,000 iu of rhEPO-beta) appeared to be safe in the early post-transplant period. The study reports only small effect sizes of rhEPO-b on adverse events, renal function, haematopoietic factors, acute rejection episodes, and the profiles of biomarkers of kidney injury post-transplant.

The dose regimen in our study was adapted from Ehrenreich et al. [13], where high levels of EPO were required to cross the blood-brain barrier to provide a high concentration in the cerebrospinal fluid. In renal patients, 
Table 1 Demographics of donors and recipients

\begin{tabular}{|c|c|c|}
\hline \multicolumn{3}{|l|}{ Donors $(n=34)$} \\
\hline & $\begin{array}{l}\text { rhEPO- } b \text { treated } \\
n=19\end{array}$ & $\begin{array}{l}\text { Placebo } \\
n=20\end{array}$ \\
\hline \multicolumn{3}{|l|}{ Demographics } \\
\hline age (yrs) median(IQR) & $52(45-58)$ & $53(46-66)$ \\
\hline male n (\%) & $10(53 \%)$ & $13(65 \%)$ \\
\hline ethnicity white n (\%) & 19 (100\%) & $20(100 \%)$ \\
\hline \multicolumn{3}{|l|}{ Cause of death $n$ (\%) } \\
\hline intra-cranialhaemorrhage & $14(74 \%)$ & $14(70 \%)$ \\
\hline other intra-cranial event & $1(5 \%)$ & $4(20 \%)$ \\
\hline extra-cranial event & $4(21 \%)$ & $2(10 \%)$ \\
\hline \multicolumn{3}{|l|}{ Donated kidney } \\
\hline ECD kidney n (\%) & 7 (37\%) & $10(50 \%)$ \\
\hline DCD kidney n (\%) & $12(63 \%)$ & $10(50 \%)$ \\
\hline inotropic support n (\%) & $12(63 \%)$ & $16(80 \%)$ \\
\hline vasopressin n (\%) & $9(47 \%)$ & $11(55 \%)$ \\
\hline final creatinine $(\mu \mathrm{mol} / \mathrm{L})$ median(IQR) & $61(51-87)$ & $77(66-96)$ \\
\hline warm ischaemic time ${ }^{1}$ mins (range) & $17(12-22)$ & $17(13-20)$ \\
\hline \multicolumn{3}{|l|}{ DCD only } \\
\hline \multicolumn{3}{|l|}{ Recipients $(n=40)$} \\
\hline \multicolumn{3}{|l|}{ Demographics } \\
\hline age (yrs) median(IQR) & $51(43-63)$ & $54(41-63)$ \\
\hline male n (\%) & $10(53 \%)$ & $14(70 \%)$ \\
\hline White & $13(68 \%)$ & 19 (95\%) \\
\hline Asian & $5(27 \%)$ & $1(5 \%)$ \\
\hline Afro-Caribbean & $1(5 \%)$ & 0 \\
\hline BMI median (IQR) & $25(23-27)$ & $25(23-29)$ \\
\hline \multicolumn{3}{|l|}{ Cause of ESRD $n(\%)$} \\
\hline glomerular disease & $8(42 \%)$ & $6(30 \%)$ \\
\hline hypertension & $1(5 \%)$ & $3(15 \%)$ \\
\hline reflux nephropathy & $4(21 \%)$ & $3(15 \%)$ \\
\hline other & $6(32 \%)$ & $8(40 \%)$ \\
\hline \multicolumn{3}{|l|}{ Mode of dialysis pre-transplant $n(\%)$} \\
\hline haemodialysis & $9(47 \%)$ & $12(60 \%)$ \\
\hline peritoneal dialysis & $8(42 \%)$ & $7(35 \%)$ \\
\hline pre-dialysis & $2(11 \%)$ & $1(5 \%)$ \\
\hline months on dialysis median(IQR) & $30(16-51)$ & $42(22-52)$ \\
\hline previous transplant n (\%) & $3(16 \%)$ & $5(25 \%)$ \\
\hline anuric pre-transplant n (\%) & $6(32 \%)$ & $7(35 \%)$ \\
\hline diabetes n (\%) & $1(5 \%)$ & 0 \\
\hline hypertension n (\%) & $17(90 \%)$ & $17(85 \%)$ \\
\hline rhEPO pre-transplant n (\%) & $17(90 \%)$ & $17(85 \%)$ \\
\hline days before transplant of last rhEPO & $5(4-11.5)$ & $4.5(1.8-11.0)$ \\
\hline
\end{tabular}

Table 1 Demographics of donors and recipients (Continued)

\begin{tabular}{|c|c|c|}
\hline \multicolumn{3}{|l|}{ PRA\% } \\
\hline $0-5$ & 14 & 14 \\
\hline $6-84$ & 4 & 5 \\
\hline$>84$ & 1 & 1 \\
\hline \multicolumn{3}{|l|}{ HLA mismatches } \\
\hline 0 & 5 & 4 \\
\hline $1-2$ & 5 & 6 \\
\hline $3-4$ & 9 & 10 \\
\hline \multirow[t]{2}{*}{ Cold ischaemic time hrs.mins (range) } & 16.52 & 16.45 \\
\hline & $(12.19-32.36)$ & $(11.12-28.42)$ \\
\hline EPO maintenance post-transplant $\mathrm{n}(\%)$ & $9(46 \%)$ & 11 (55\%) \\
\hline Blood transfusions post-transplant (n) & 6 & 11 \\
\hline Packed red cell post-transplant (units) & $1.2 \pm 0.5$ & $1.9 \pm 0.6$ \\
\hline $\begin{array}{l}\text { Acute rejection episodes in } 3 \text { mths } \\
\text { post-transplant }\end{array}$ & 5 & 3 \\
\hline $\begin{array}{l}{ }^{1} \text { warm ischaemic time in } \mathrm{DCD} \text { was defined } \\
\text { cold perfusion. } \\
\mathrm{IQR}=\text { interquartile range, } \mathrm{BMI}=\text { body mass } \\
\text { disease, } \mathrm{PRA}=\text { panel reactive antibodies. }\end{array}$ & $\begin{array}{l}\text { as the time from } \\
\text { ndex, ESRD = en }\end{array}$ & $\begin{array}{l}\text { stole to in-situ } \\
\text { ge renal }\end{array}$ \\
\hline
\end{tabular}

the maximum recommended dose in renal failure is 720 $\mathrm{iu} / \mathrm{kg} /$ week [24], which in the average $70 \mathrm{~kg}$ patient, is half the dose administered in this study. Furthermore, mathematical modelling in healthy volunteers has demonstrated that a similar dose $(1000 \mathrm{U} / \mathrm{kg})$ resulted in $>98 \%$ occupation of EPO receptors, which persisted for 2 days following the dose [25]. The majority of the recipients in this study were receiving maintenance rhEPO for anaemia associated with end-stage renal failure, though administration of rhEPO stopped more than 2 days prior to transplant in all but 7 recipients. It is conceivable that tissue protection was afforded by low levels of rhEPO to both groups, and thus confounded the outcome, with a dose ceiling effect for EPO. However, the retrospective review from Mohiuddin et al. [26] of patients receiving anaemia maintenance doses of rhEPO at the time of transplantation found no difference in the DGF rate or haemoglobin levels compared to those patients not receiving rhEPO, out to three months post-transplant.

Song et al. [27] administered $300 \mathrm{mg} / \mathrm{kg}$ of erythropoietin-beta IV to 36 adults undergoing coronary artery bypass grafting at induction of anaesthesia and noted a reduction in the incidence of acute kidney injury (EPO 8\% vs Placebo $29 \%, \mathrm{p}=0.03$ ), defined as a $50 \%$ increase in serum creatinine over baseline in the first 5 post-operative days. However Poulsen et al. [28] examined the effect of high dose EPO (500 iu/kg IV 12-18 hrs pre-op and at induction) in patients undergoing coronary artery bypass with no apparent difference between treatment and placebo groups with regard to serum creatinine. Martinez 
Table 2 Graft function and dialysis early post-transplantation

\begin{tabular}{llll}
\hline & rhEPO- $\boldsymbol{b}$ group $(\boldsymbol{n}=\mathbf{1 9})$ & Placebo group $(\boldsymbol{n}=\mathbf{2 0})$ & $\mathbf{R R}(\mathbf{C l}) \mathbf{p}$ \\
\hline Primary non-function & 0 & 0 & $\mathrm{RR}=1.0(0.5-1.6) \mathrm{p}=0.93$ \\
Delayed graft function $n(\%)$ & $10(53 \%)$ & $11(55 \%)$ & $\mathrm{RR}=1.1(0.5-1.9) \mathrm{p}=0.73$ \\
Slow graft function $n(\%)$ & $6(32 \%)$ & $5(25 \%)$ & \\
Days to first dialysis* & $1(1-3)$ & $1(1-3)$ & \\
Number of dialysis episodes* & $3(1-17)$ & $4(1-19)$ & $8(1-35)$ \\
Days to last dialysis* & $7(1-41)$ & & \\
\hline
\end{tabular}

*median (IQR).

reported a French multicentre placebo controlled trial examined the effect of 40,000U EPO IV administered before kidney transplantation, at 12 hours, 7 days and 14 days post-operatively on the incidence of DGF [22]. There was no difference in DGF rates between the groups (EPO 32\% vs placebo 29\%), with similar eGFRs at 1 month post-implantation. A retrospective study in France compared recipients on $250 \mathrm{U} / \mathrm{kg} /$ week of EPO at the time of transplantation to recipients not receiving EPO and found no difference in graft function or haemoglobin level at 1 month [29]. Furthermore, the German multi-centre EPO Stroke Trial, a Phase II/III trial designed to reproduce the promising results of the earlier EPO Stroke Study (improved clinical recovery in EPO treated patients with ischemic stroke), was a negative trial that also raised safety concerns [30]. Aydin et al.
[23] reported a 12-month, randomized, double-blind, placebo- controlled trial of high-dose recombinant human erythropoietin-b (Epoetin) in 92 donation after cardiac death kidney transplant recipients. Patients were randomized to receive an intravenous bolus of Epoetin $\left(3.3 \times 10^{4} \mathrm{IU} ; \mathrm{n}=45\right)$ or placebo (saline $0.9 \%$ solution; $\mathrm{n}=47$ ) on 3 consecutive days, starting $3-4 \mathrm{~h}$ before the transplantation and $24 \mathrm{~h}$ and $48 \mathrm{~h}$ after reperfusion. Results showed no differences in the incidence or duration of delayed graft function and/or primary non-function (Epoetin 77.8 vs. placebo 78.7\%, p = 1.00) though Epoetin treatment significantly increased the risk of thrombotic events at 1 month and 1 year (Epoetin 24.4\% vs. placebo $6.4 \%, \mathrm{p}=0.02$ ).

In patients with an acute ST-segment elevation myocardial infarction a single intravenous bolus of EPO-alpha
A

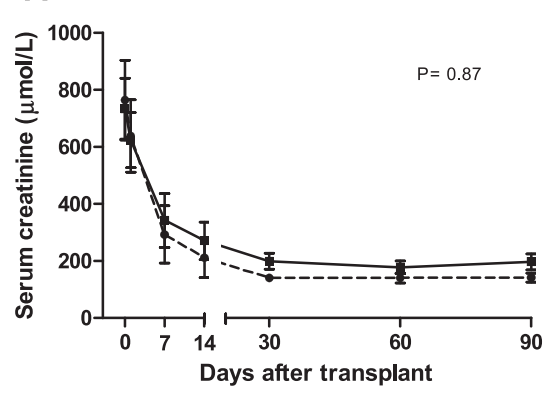

C

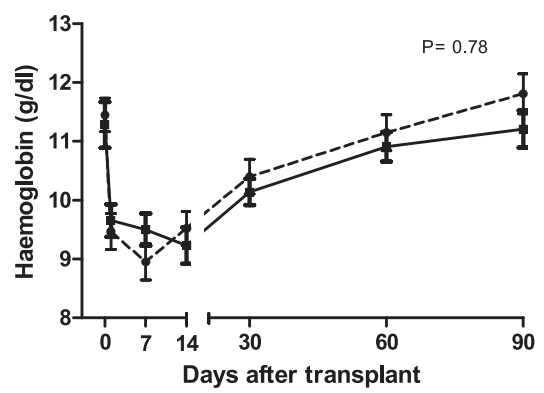

B

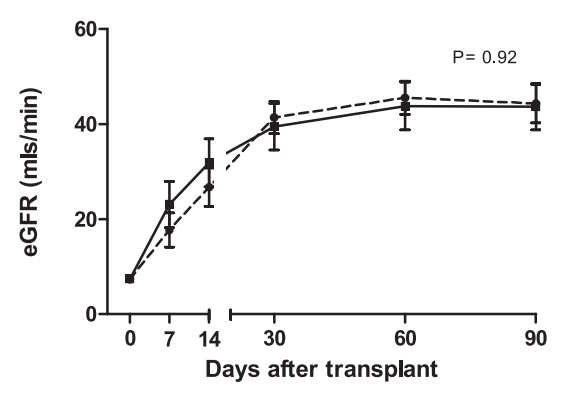

D

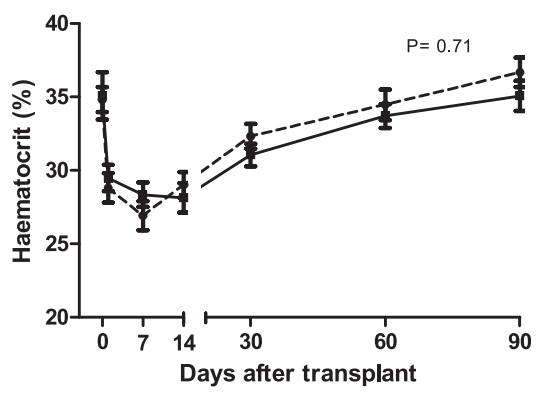

Figure 2 Sequential serum creatinine, 4-variable MDRD eGFR, haemoglobin and haematocrit profiles. (A) serum creatinine and (B) eGFR (4v MDRD). Renal function was similar in the EPO and placebo treated patients, with no significant differences. (C) Haemoglobin and (D) Haematocrit during the first 3 months post-transplant. Haematocrit levels were similar in the EPO and placebo treated patients with no significant differences. EPO treated group placebo group Data expressed as mean \pm SEM, ANOVA. 

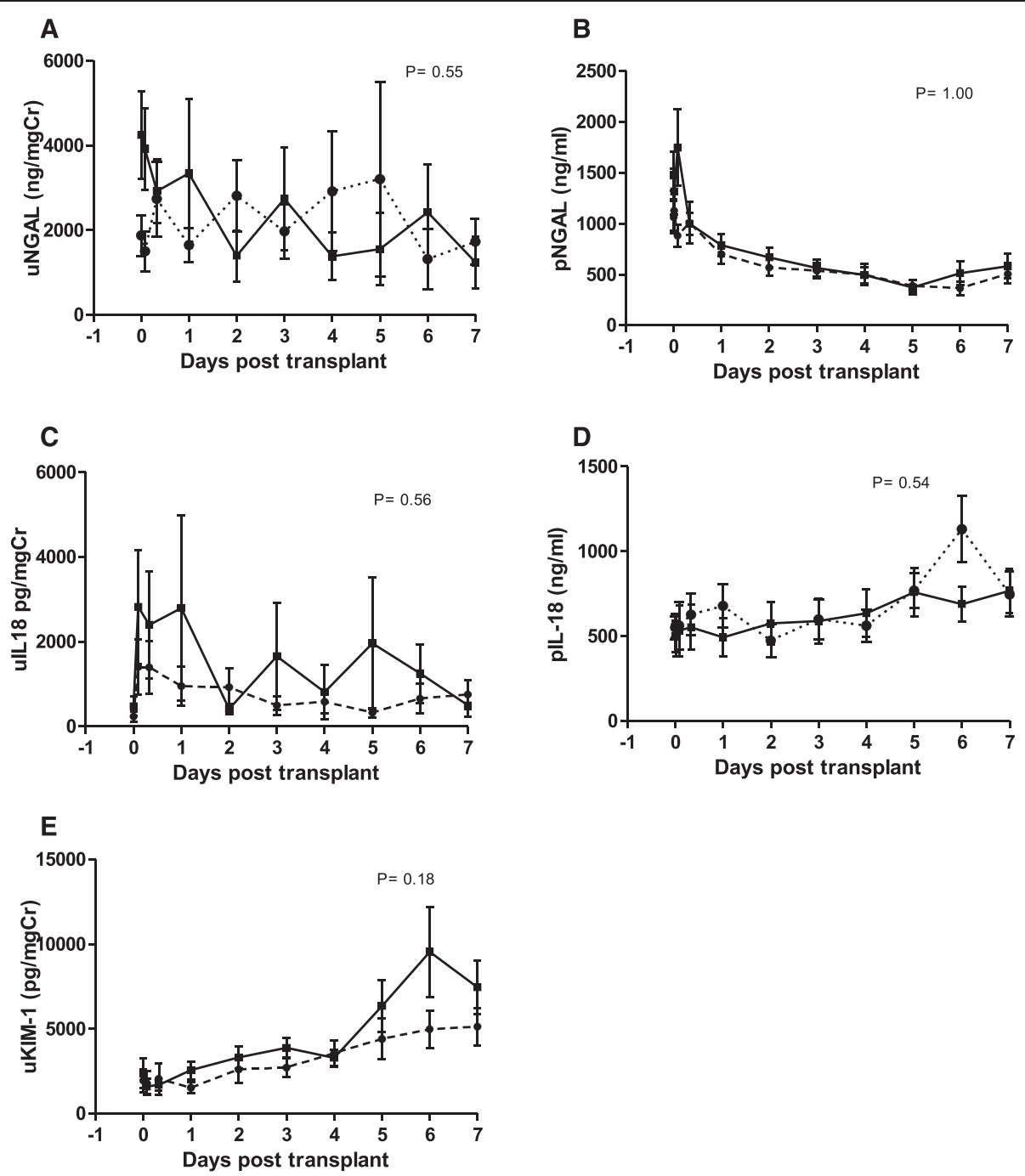

Figure 3 Biomarkers of kidney injury (A) uNGAL ng/mgCr (B) pNGAL (ng/ml) (C) ulL-18 pg/mgCr (D) plL-18 (ng/ml) (E) uKIM-1 pg/mgCr. rhEPO treated group placebo group Data shown as means +/- SEM. P values are for an overall difference between EPO and placebo treated, based on a mixed-effect ANOVA model.

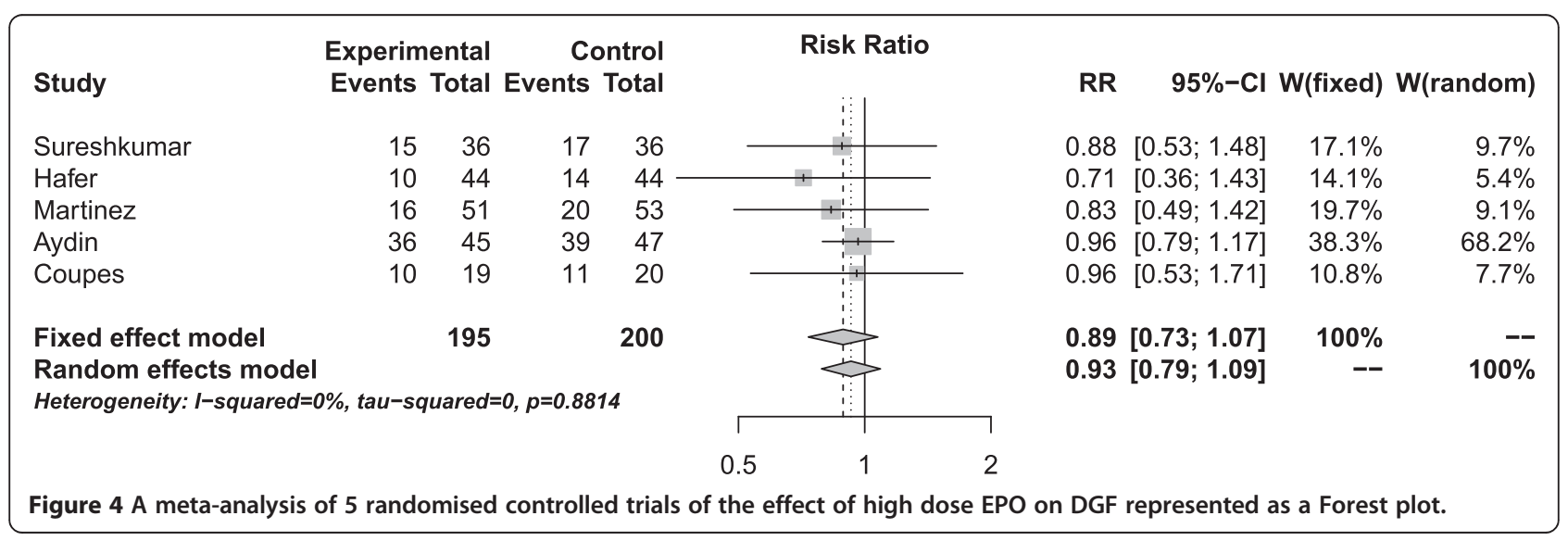


within 4 hours of percutaneous coronary intervention did not reduce infarct size [31].

Two other randomised controlled trials investigating high dose EPO in renal transplantation have been published recently. Sureshkumar et al. [20] conducted a randomised double blind clinical trial where the primary end point was the level of graft function in the early posttransplant period. Thirty-six patients in each group were included in the final analysis and their data gave similar event rates to the study reported here, with a RR for DGF of 0.88 (0.53-1.48). There were no clinically demonstrable beneficial effects of high dose EPO-alpha given intraarterially during the early reperfusion phase in deceased donor kidney recipients, in terms of reducing the incidence of DGF or improving short-term allograft function. The authors also measured two biomarkers (NGAL and IL-18) post transplantation and found similar levels in the EPO treated group versus the control group. They did not report an increase in adverse events in the EPO treated group.

In the second study Hafer et al. [21] evaluated high dose EPO-alpha administered intra-and post-operatively to recipients of deceased donor kidneys, with a primary study end point of allograft function 6 weeks posttransplant. The study recruited 45 patients to each arm. There was no significant effect of EPO-alpha on either long-term graft function (eGFR at 12 months) or histology (protocol biopsies at 6 weeks and 6 months), with a RR for DGF again similar to our study at 0.71 (0.36-1.43), but with a lower overall event rate of $27 \%$.

The doses of rhEPO used by Sureshkumar et al. (40,000 iu rhEPO-alpha injected into the iliac artery) and Hafer et al. (3 doses of 40,000 iu rhEPO-alpha) were similar to our study (3 doses of 33,000 iu rhEPO-beta). It is conceivable that a lack of efficacy is a consequence of the timing of EPO administration. Injury prior to reperfusion is multi-factorial and due to recurrent insults to the kidney rather than a single ischaemia reperfusion event. Typically injury begins with peri-mortem events including, severe hypertension or hypotension and nephrotoxic agents. Retrieval of the kidneys is associated with warm ischaemia, cold ischaemia and the anastomotic ischaemic phase. The lack of efficacy in these studies may be due to the delay in rhEPO-b administration until reperfusion. However, therapeutic intervention in the donor, prior to organ retrieval and storage, would impact on all organs donated and prevent any potential recipients from declining involvement in the study without declining organ transplantation. It was not possible to intervene during cold storage firstly because we did not have access to machine perfusion technology at the time, and secondly the potential recipient would not have been able to decline involvement in the study. We decided to intervene immediately prior to reperfusion, with the knowledge that significant injury to the kidney may have already occurred, but based on the experimental evidence, intervention could still be beneficial to the graft. The participants in our study received kidneys from DCD and ECD donors. In the study from Sureshkumar et al. the kidneys were from ECD donors in only $46 \%$ of the cases. The donor details were not presented in the study from Hafer et al., though their exclusion criteria included immunological loss of a previous graft, and cold ischaemic time of longer than 24 hours.

\section{Conclusions}

Taking the five studies together, a range of quality of donated kidneys has been examined and the evidence appears convincing that high dose rhEPO in deceased kidney transplants, although well tolerated, has little effect on DGF, early or later allograft function, graft histology, or levels of biomarkers of kidney injury, including NGAL, IL-18 and KIM-1. Additionally, concerns were raised over the increased number of thrombotic events in the EPO treated groups in some of the trials. A metaanalysis of the five trials yielded an overall estimate of the RR for DGF of $0.89(\mathrm{CI}=0.73 ; 1.07)$, a modest effect favouring EPO but not demonstrating a significant difference. At a time when there is obvious need to maximise the lifespan of donated organs it is disappointing that the promising experimental evidence of rhEPO tissue protection does not readily translate into the clinical setting of transplantation.

\section{Methods}

\section{Ethical approval}

The study was conducted in accordance with the ethical principles of the Declaration of Helsinki and was consistent with the International Conference on Harmonization of Good Clinical Practice. The clinical and research activities reported are consistent with the Principles of the Declaration of Istanbul as outlined in the Declaration of Istanbul on Organ Trafficking and Transplant Tourism. The study was approved by the Central Manchester Research Ethics Committee (07/Q1407/94), the Medicines for Human use Regulatory Authority (EuDract no. 2006-005373-22), and registered with the ISRCTN (number 85447324; 19/08/09). Informed consent was obtained from each patient. The manuscript adheres to CONSORT guidelines for reporting clinical trials [32].

\section{Patients}

Patients were eligible if aged 18 years or more, able to give consent, and in receipt of a Maastricht category III, (awaiting cardio-circulatory death after withdrawal of treatment), a Maastricht category IV (cardio-circulatory death in a brain dead donor), a kidney from an extended criteria donor (defined as equal to or greater than 60 years 
old, or 50-59 years with combinations of cerebrovascular accident, hypertension or serum creatinine greater than $133 \mu \mathrm{mol} / \mathrm{l}$, or a kidney with a cold ischaemic time greater than 24 hours). Exclusion criteria included inability to consent, pregnancy, breastfeeding, acute infection, previous intolerance of the trial drug, a diastolic blood pressure $>100 \mathrm{~mm} / \mathrm{Hg}$ pre-transplantation, or initially a haemoglobin level $=$ or $>13 \mathrm{~g} / \mathrm{dl}$. However, it became clear that a haemoglobin cut-off of $13 \mathrm{~g} / \mathrm{dl}$ would exclude approximately one third of otherwise eligible participants. A review of the pre-operative haemoglobin levels of adults transplanted at this centre in 2007 reported a mean preop haemoglobin of $12.2 \mathrm{~g} / \mathrm{dl}$, with a range of 7.4-17.7 g/dl, and a mean decrease of $2.4 \mathrm{~g} / \mathrm{dl}$ within 24 hours of surgery. As a result, the haemoglobin exclusion criterion was reset to $\geq 15 \mathrm{~g} / \mathrm{dl}$, as a substantial amendment to the protocol with ethical and regulatory authority approval. All patients received immunosuppression as per unit protocol. Induction immunosuppression consisted of basiliximab $20 \mathrm{mg}$ intravenously on day 0 and day 4 , as well as a single dose of methylprednisolone $1 \mathrm{~g}$ given intra-operatively. Maintenance immunosuppression consisted of tacrolimus (Prograf $f^{\circ}$ ), prednisolone and mycophenolate mofetil $\left(\right.$ Cellcept $\left.^{\circ}\right)$. DGF was defined as the need for haemodialysis or peritoneal dialysis within the first seven days post transplantation, and slow graft function was defined as a creatinine reduction ratio at day 7 of $<70 \%$ [33].

\section{Randomisation and blinding}

Eligible patients were randomly assigned by the trial Pharmacy using a computer-generated list to receive either rhEPO-b (Neorecormon ${ }^{\circ}$ Roche) or $0.9 \%$ saline. All study participants and the clinical team were blinded to the trial drug for the duration of the study. Pharmacovigilance was undertaken by PDMS Roche Products Limited.

\section{Sample collection and processing}

The first dose of rhEPO-b (33,000 iu) (Neorecormon ${ }^{\circ}$ Roche) or $0.9 \%$ saline were administered intra-operatively in a $100 \mathrm{ml}$ intra-venous infusion over 15 minutes, as clamps were released to allow graft reperfusion. The second and third infusions (each 33,000 iu) were given at 24 hour intervals post-operatively, making a total rhEPOb dose of approximately 100,000 iu over approximately 48 hours. Prior to reperfusion, a $20 \mathrm{ml}$ systemic blood sample was collected via the central line (the prereperfusion sample). The post-reperfusion $20 \mathrm{ml}$ blood sample was collected approximately 15 minutes following reperfusion. $10 \mathrm{ml}$ blood samples were collected at 2,8 and 24 hours, and daily for the first 7 days postoperatively, coinciding with venepuncture for routine care where possible. Blood samples were centrifuged at
$2000 \mathrm{rpm}$ for 10 minutes to separate the plasma, which was aliquoted and stored at $-80 \mathrm{C}$. Urine samples were collected at similar time points where possible, centrifuged at $2000 \mathrm{rpm}$ for 5 minutes, aliquoted and stored at $-80 \mathrm{C}$. Samples were batched for analysis of biomarkers.

\section{Measurement of biomarkers}

Plasma NGAL (pNGAL) and urine NGAL (uNGAL) were measured by immunoassay using the Duoset DY1757, and urine KIM-1 (uKIM-1) using the duoset DY1750, R\&D Systems, OXON UK, following the manufacturer's guidelines. Mature IL-18 in plasma and urine was measured using an in-house immunoassay (capture antibody - Clone 125-2H, detection antibody Clone 159-12B, and standard - rHuIL-18, MBL, Medical and Biological Labs co. Ltd, Nagoya, Japan). Sample concentrations in all assays were calculated from a 4parameter standard curve (SOFTmax PRO v4 software, Molecular Devices, Ca 94089). Biomarkers in urine were corrected for creatinine concentration in the sample. An internal standard was included on each assay plate confirming an inter-assay coefficient of variation (CV) of $<20 \%$ and an intra-assay CV of $<10 \%$.

\section{Sample size and statistical analysis}

As a pilot, the study had no formal power calculation, but was designed to test the safety of delivering the intervention, to describe effect sizes on the measured variables (adverse events, renal function, haematopoietic markers, and acute rejection episodes), and to evaluate the profiles of three biomarkers of kidney injury. A sample size of 20 per arm was chosen on the basis of feasibility and to gather sufficient data to design and power a definitive trial [34].

Data analysis was performed using GraphPad Prism 5. Results were presented as median \pm interquartile range, or as percentages as appropriate. Mann-Whitney U tests were used to compare continuous variables between groups. Categorical data was analysed using a Fisher's exact test to generate a risk ratio (RR) and confidence interval (CI). Clinical and biomarkers assessed at multiple times were compared using mixed-effect ANOVA models to allow for correlations between repeat measures using the lmer package in the R statistical environment [35]. A meta-analysis including this trial and those described by Sureshkumar et al. [20], Hafer et al. [21], Martinez et al. [22] and Aydin et al. [23] was conducted to derive a pooled RR estimate using the MantelHaenszel estimator and a random effects estimator, and the meta package in R. A two- tailed significance level of 0.05 was used throughout.

\section{Abbreviations}

DCD: Donation after circulatory death; DGF: Delayed graft function; ECD: Extended criteria donor; IRI: Ischaemia reperfusion injury; KIM-1: Kidney 
injury molecule-1; NGAL: Neutrophil gelatinase-associated lipocalin; rhEPO-b: rhErythropoietin-beta; SGF: Slow graft function.

\section{Competing interests}

The authors have no competing interests to declare.

\section{Authors' contributions}

All authors participated in the research design. BC, DdeF, SAR, PECB and MLP participated in the writing of the paper. BC, DdeF, IR and HR participated in the performance of the research. BC, DdeF and SAR participated in data analysis. All authors read and approved the final manuscript.

\section{Authors' information}

Beatrice Coupes and Declan $\mathrm{G}$ de Freitas wish to be considered as joint first authors.

\section{Acknowledgements}

Dr D de Freitas was in receipt of an Astellas Transplant Fellowship award. Dr $M$ Picton was in receipt of unrestricted educational grants from Amgen and Roche. Roche supplied Neorecormon ${ }^{\circledast}$ for the study, and undertook the pharmacovigilance. BC, IR, PECB and MP held substantive contracts with Central Manchester University Hospitals Foundation Trust, and SAR with the University of Manchester. Funding support for the study performance was provided by Central Manchester University Hospital Foundation Trust Biomedical Research Centre in the form of a research grant awarded to the team in open competition. The authors wish to acknowledge the dedicated work of Dr Clare Griffin, Sisters Linda Birtles and Ruth Topping. We are very grateful to our patients who consented to take part in the study.

\section{Funding}

Dr D de Freitas was in receipt of an Astellas Transplant Fellowship award. Dr $M$ Picton was in receipt of unrestricted educational grants from Amgen and Roche. Roche supplied Neorecormon ${ }^{\circledR}$ for the study, and undertook the pharmacovigilance. BC, IR, PECB and MP held substantive contracts with Central Manchester University Hospitals Foundation Trust, and SAR with the University of Manchester. Funding support for the study performance was provided by Central Manchester University Hospital Foundation Trust Biomedical Research Centre in the form of a research grant awarded to the team in open competition.

\section{Author details}

'Department of Renal Medicine, Manchester Royal Infirmary, Oxford Rd, Manchester M13 9WL, UK. ${ }^{2}$ Centre for Biostatistics, University of Manchester, Manchester M13 9PL, UK. ${ }^{3}$ Department of Surgery, Manchester Royal Infirmary, Oxford Rd, Manchester M13 9WL, UK.

\section{Received: 25 February 2014 Accepted: 30 December 2014} Published online: 03 February 2015

\section{References}

1. NHS Blood and Transplant Annual Report. 2012. http://www.odt.nhs.uk/ uk-transplant-registry/annual-activity-report.

2. Port FK, Bragg-Gresham JL, Metzger RA, Dykstra DM, Gillespie BW, Young EW, et al. Donor characteristics associated with reduced graft survival: an approach to expanding the pool of kidney donors. Transplantation. 2002;74:1281-6.

3. Leichtman AB, Cohen D, Keith D, O'Connor K, Goldstein M, McBride V, et al. Kidney and pancreas transplantation in the United States, 1997-2006: the HRSA Breakthrough Collaboratives and the 58 DSA Challenge. Am J Transplant. 2008;8(4 Pt 2):946-57.

4. Moreno F, Sanz-Guajardo D, López-Gómez JM, Jofre R, Valderrábano F. Increasing the hematocrit has a beneficial effect on quality of life and is safe in selected hemodialysis patients. Spanish Cooperative Renal Patients Quality of Life Study Group of the Spanish Society of Nephrology. J Am Soc Nephrol. 2000;11:335-42.

5. Bárány P, Pettersson E, Bergström J. Erythropoietin treatment improves quality of life in hemodialysis patients. Scand J Urol Nephrol Suppl. 1990;131:55-60.
6. Ishii Y, Sawada T, Murakami T, Sakuraoka Y, Shiraki T, Shimizu A, et al. Renoprotective effect of erythropoietin against ischaemia-reperfusion injury in a non-human primate model. Nephrol Dial Transplant. 2011;26:1157-62.

7. Forman CJ, Johnson DW, Nicol DL. Erythropoietin administration protects against functional impairment and cell death after ischaemic renal injury in pigs. BJU Int. 2007;99:162-5.

8. Lee SH, Li C, Lim SW, Ahn KO, Choi BS, Kim YS, et al. Attenuation of interstitial inflammation and fibrosis by recombinant human erythropoietin in chronic cyclosporine nephropathy. Am J Nephrol. 2005;25:64-76.

9. Yang CW, Li C, Jung JY, Shin SJ, Choi BS, Lim SW, et al. Preconditioning with erythropoietin protects against subsequent ischemia-reperfusion injury in rat kidney 2. FASEB J. 2003;17:1754-5. 1530-6860 (Electronic).

10. Patel NS, Sharples EJ, Cuzzocrea S, Chatterjee PK, Britti D, Yaqoob MM, et al. Pretreatment with EPO reduces the injury and dysfunction caused by ischemia/reperfusion in the mouse kidney in vivo 1. Kidney Int. 2004;66:983-9. 0085-2538 (Print).

11. Abdelrahman M, Sharples EJ, McDonald MC, Collin M, Patel NSA, Yaqoob $\mathrm{MM}$, et al. Erythropoietin attenuates the tissue injury associated with hemorrhagic shock and myocardial ischemia. Shock. 2004;22:63-9.

12. Sharples EJ, Patel N, Brown P, Stewart K, Mota-Philipe H, Sheaff M, et al. Erythropoietin protects the kidney against the injury and dysfunction caused by ischemia-reperfusion. J Am Soc Nephrol. 2004;15:2115-24.

13. Ehrenreich $H$, Hasselblatt M, Dembowski C, Cepek L, Lewczuk P, Stiefel M, et al. Erythropoietin therapy for acute stroke is both safe and beneficial. Mol Med. 2002:8:495-505.

14. Roche Products Ltd. SmPC for NeoRecormon ${ }^{\oplus: 4.4}$

15. Mishra J, Ma Q, Prada A, Mitsnefes M, Zahedi K, Yang J, et al. Identification of neutrophil gelatinase-associated lipocalin as a novel early urinary biomarker for ischemic renal injury. J Am Soc Nephrol. 2003;14:2534-43.

16. Mishra J, Mori K, Ma Q, Kelly C, Yang J, Mitsnefes M, et al. Amelioration of ischemic acute renal injury by neutrophil gelatinase-associated lipocalin. J Am Soc Nephrol. 2004;15:3073-82.

17. Parikh CR, Abraham E, Ancukiewicz M, Edelstein CL. Urine IL-18 is an early diagnostic marker for acute kidney injury and predicts mortality in the intensive care unit. J Am Soc Nephrol. 2005;16:3046-52.

18. Ichimura T, Bonventre JV, Bailly V, Wei H, Hession CA, Cate RL, et al. Kidney injury molecule-1 (KIM-1), a putative epithelial cell adhesion molecule containing a novel immunoglobulin domain, is up-regulated in renal cells after injury. J Biol Chem. 1998;273:4135-42.

19. Vaidya VS, Ozer JS, Dieterle F, Collings FB, Ramirez V, Troth S, et al. Kidney injury molecule-1 outperforms traditional biomarkers of kidney injury in preclinical biomarker qualification studies. Nat Biotechnol. 2010;28:478-85.

20. Sureshkumar KK, Hussain SM, Ko TY, Thai NL, Marcus RJ. Effect of high-dose erythropoietin on graft function after kidney transplantation: a randomized, double-blind clinical trial. Clin J Am Soc Nephrol. 2012;7:1498-506.

21. Hafer C, Becker T, Kielstein JT, Bahlmann E, Schwarz A, Grinzoff N, et al. High-dose erythropoietin has no effect on short- or long-term graft function following deceased donor kidney transplantation. Kidney Int. 2012;81:314-20.

22. Martinez F, Kamar N, Pallet N, Lang P, Durrbach A, Lebranchu Y, et al. High dose epoetin beta in the first weeks following renal transplantation and delayed graft function: Results of the Neo-PDGF Study. Am J Transplant. 2010;10:1695-700.

23. Aydin Z, Mallat MJK, Schaapherder a FM, van Zonneveld a J, van Kooten C, Rabelink TJ, et al. Randomized trial of short-course high-dose erythropoietin in donation after cardiac death kidney transplant recipients. Am J Transplant. 2012;12:1793-800.

24. Roche Products Ltd. Neorecormin summary of product characteristics. 2010.

25. Krzyzanski W, Wyska E. Pharmacokinetics and pharmacodynamics of erythropoietin receptor in healthy volunteers. Naunyn Schmiedebergs Arch Pharmacol. 2008;377:637-45.

26. Mohiuddin MK, El-Asir L, Gupta A, Brown A, Torpey N, Ward M, et al. Perioperative erythropoietin efficacy in renal transplantation. Transplant Proc. 2006;39:132-4.

27. Song YR, Lee T, You SJ, Chin HJ, Chae D-W, Lim C, et al. Prevention of acute kidney injury by erythropoietin in patients undergoing coronary artery bypass grafting: a pilot study. Am J Nephrol. 2009;30:253-60.

28. Poulsen TD, Andersen LW, Steinbrüchel D, Gøtze JP, Jørgensen OS, Olsen NV. Two large preoperative doses of erythropoietin do not reduce the systemic inflammatory response to cardiac surgery. J Cardiothorac Vasc Anesth. 2009;23:316-23. 
29. Kamar N, Reboux AH, Cointault O, Esposito L, Cardeau-Desangles I, Lavayssiere $L$, et al. Impact of very early high doses of recombinant erythropoietin on anemia and allograft function in de novo kidney-transplant patients 1. Transpl Int. 2010;23:277-84. 1432-2277 (Electronic).

30. Ehrenreich $H$, Weissenborn K, Prange $H$, Schneider D, Weimar C, Wartenberg $\mathrm{K}$, et al. Recombinant human erythropoietin in the treatment of acute ischemic stroke 2. Stroke. 2009;40:e647-56. 1524-4628 (Electronic).

31. Prunier F, Bière L, Gilard M, Boschat J, Mouquet F, Bauchart J-J, et al. Single high-dose erythropoietin administration immediately after reperfusion in patients with ST-segment elevation myocardial infarction: results of the erythropoietin in myocardial infarction trial. Am Heart J. 2012;163:200-7. e1.

32. Schulz KF, Altman DG, Moher D. CONSORT 2010 statement: updated guidelines for reporting parallel group randomized trials. Ann Intern Med. 2010;152:726-32.

33. Johnston O, O'kelly P, Spencer S, Donohoe J, Walshe JJ, Little DM, et al. Reduced graft function (with or without dialysis) vs immediate graft function-a comparison of long-term renal allograft survival 1. Nephrol Dial Transplant. 2006;21:2270-4. 0931-0509 (Print).

34. Lancaster GA, Dodd S, Williamson PR. Design and analysis of pilot studies: recommendations for good practice. JEval Clin Pract. 2004;10:307-12. 1356-1294 (Print).

35. R Core Team. R: a language and environment for statistical computing Vienna, Austria: R Foundation for Statistical Computing; 2013. URL http://www.R-project.org/.

\section{Submit your next manuscript to BioMed Central and take full advantage of:}

- Convenient online submission

- Thorough peer review

- No space constraints or color figure charges

- Immediate publication on acceptance

- Inclusion in PubMed, CAS, Scopus and Google Scholar

- Research which is freely available for redistribution 